\title{
Study on the Influence of Tourists' Value on Sustainable Development of Huizhou Traditional Villages-- A Case of Hongcun and Xidi
}

\author{
QI Wei ${ }^{1}$, LI Mimi ${ }^{2 *}$, XIAO Honggen ${ }^{2}$, ZHANG Jinhe ${ }^{3}$ \\ ${ }^{1}$ Anhui Technical College of Industry and Economy, Hefei, Anhui \\ ${ }^{2}$ School of Hotel and Tourism Management, The Hong Kong Polytechnic University, Kowloon, Hong Kong \\ ${ }^{3}$ School of Geography and Ocean Science, Nanjing University, Nanjing, Jiangsu
}

\begin{abstract}
The tourists' value of traditional village representing personal values, influences the tourists' behavior deeply. This paper, with the soft ladder method of MEC theory from the perspective of the tourist, studies the value of tourists born in the $60 \mathrm{~s}, 70 \mathrm{~s}, 80 \mathrm{~s}$, and $90 \mathrm{~s}$ of the traditional villages in Hongcun and Xidi, which indicates $39 \mathrm{MEC}$ value chains, and reveals 11 important attributes of Huizhou traditional villages, 16 tourism results, and 9 types of tourists' values. With constructing a sustainable development model of Huizhou traditional villages based on tourists' value, it shows an inherent interaction between tourists' value and traditional village attributes subdividing the tourism products and marketing channels of Huizhou traditional villages, which is of great significance to the sustainable development of traditional villages in Huizhou.
\end{abstract}

\section{Introduction}

Traditional villages refer to the rural communities, with historical inheritance of certain ideology, culture, customs, art and social-economic values, rural communities, formed by people with common values who gather together with agriculture as the basic content of economic activities, including ancient villages, cultural historical villages, world heritage villages, etc.[1-3].

A series of profound changes in the post-modern society make tourists yearn for the countryside, and experience rural symbols which are the attributes of rural tourism, to satisfy tourists' certain psychological pursuits which means for tourists the consequences of tourism, whose positive meaning is the tourism value of tourists to the countryside. This tourism ${ }^{1}$ consumption process is the embodiment of the chain relationship "attribute-result-value" of the "means-end chain" theory[4-6]. As Traditional village tourism is the important part of rural tourism, consequently, from the perspective of tourism consumers, what is the attraction of tourism development in traditional villages to tourists, and what is the tourism value of traditional villages to tourists? What kind of correspondence does there exist between the attributes of traditional villages and tourists' value? Therefore, this study attempts to explore the tourism value pursued by tourists and the internal connection between value and the attributes of traditional villages, to activate traditional village tourism and realize the sustainable development of traditional villages.

\section{Theoretical Basis}

\subsection{The Sustainable Development of Traditional Villages}

At present, scholars' research on the sustainable development of traditional village tourism covers the sustainable development of cultural tourism, ecological environment, economic construction, and social governance[7], which achieves fruitful results, including "Community Participation + Enterprise Operation" Model[8], Typical model of "ditch economy"[9], "Diversified mixed effect" model[10], "Urbanization, Community Participation and Protected Areas" model[11], which explores the balanced relationship between traditional village protection and tourism development from the background of traditional village resources and the stakeholders of traditional village tourism development.

Resources are the basis for the development of tourism in traditional villages. And traditional villages are the cohesion of Chinese culture and spirit. The

\footnotetext{
${ }^{1}$ Qi Wei（1974—) , Tongcheng, Anhui, Doctor Degree, Associate Professor, qiwei.edu@163.com

*Li Mimi(1978 - ), Datong, Shanxi, Doctor Degree, Associate Professor, Doctoral Supervisor, hmmli@polyu.edu.hk

Xiao Honggen (1965-), Jiangle, Fujian, Doctor Degree, Professor,Doctoral Supervisor,honggen.xiao@polyu.edu.hk

Zhang Jinhe (1970-), Wangjiang, Anhui, Professor, Doctoral Supervisor, zhangjinhe@nju.edu.cn
} 
cultural heritage resources of ancient villages can be protected in the usage of tourism [12], and tourism can activate and protect traditional villages [13]. Resource authenticity is the foundation of traditional village protection and tourism development. Xu Wei and Li Yao (2011) [14]conducted in-depth interviews with tourists in ancient villages in southern Anhui and found that the differentiated development of resource authenticity promoted the sustainable development of ancient villages.

Stakeholders in the tourism development of traditional villages can be divided into three categories: "core stakeholders, dormant stakeholders, and marginal stakeholders". There are differences and connections among the stakeholders [15].The cultural and environmental aspects of ancient villages are the common concerns of different stakeholders[16]. Tourist is the main part of traditional village tourism, and local government and community residents are the two of the most important factors influencing the sustainable development of traditional Chinese village tourism . Both of them should consider their respective interests and build a healthy interaction mechanism to promote the sustainable development of tourism in traditional villages. The essence of traditional village tourism development is a game among stakeholders such as local governments, residents, tourism operators and tourists. In this process, the government is the decisive factor [17], and multiple stakeholders can evolve in symbiosis to achieve the evolution of symmetrical reciprocity and integrated symbiosis [18].

Tourists' perception of tourism in ancient villages has an important impact on the development of tourism in ancient villages[19].As the Multidimensionality of perceived value of tourists in traditional villages, there is the diversity of the contribution value of each dimension, and meanwhile, the relevance of different dimensions[20]. The quality of tourism services and tourism experience are the main influential factors that affect the perception of tourists in traditional villages [21]. Due to traditional folk culture, the soul of tourism in ancient villages, tourism development should not be excessively commercial. The sustainable development model of ancient village tourism should stay in step with the transformation of market demand [22].

Residents, the masters and owners of traditional villages, are regarded as the starting point for the protection of tourism resources in traditional villages [23]. The support and satisfaction of residents promotes the development of tourism in traditional villages [24]. The ancient villages obtain the vitality of sustainable development from the internal factors of the residents and the external factors of the market [25].At present, the perceptions of tourism development of traditional villages residents become mature and rational gradually, and the influence of communities in the tourism development of traditional villages has gradually emerged [26].The improvement of community flexibility and local wisdom have promoted the sustainable development of tourism in traditional villages [27-28]. The ancient villages like Xidi,Hongcun, and Nanping promoted the sustainable development of the ancient villages by improving the residents' community participation, income level, community satisfaction, community pride and identity, and enhancing the local attachment of residents to the ancient villages[29]. Through the adjustment of government policies and management models, sustainable development indicators of "community participation in management level" and "equity of benefit distribution" can be optimized[30].

\subsection{Tourists' Value}

Value refers to the meaning of the object existence, attributes and changes of the object relative to the subject[31]. It is also a state of subject-object relationship based on the scale of the subject [32]. It is the affirmative and positive significance of a certain attribute of the object to the needs of the subject. The value can be divided into two categories: the value of the purpose and the value of the means [33]. The former implies that the value formed by the object satisfying the subject's needs with the achievement of the purpose of the subject's activities, and the latter refers to the value which is formed for the object meeting the higher goal needs of subject, to achieve the higher goal of the subject's activities[32], which is the ultimate value. It is the value of subject tourists that tourists would obtain the tourism result that alters from subject to object through the attributes of the objective traditional village in the traditional village tourism activities, to realize the significance of the change from the subject tourists to the object traditional village. It can be inferred that the consumption process of tourists to traditional villages is consistent with the value chain relationship of "attribute-result-value"[6] of Means End Chain Theory (Means End Chain Theory, MEC). Therefore, this study attempts to trace the tourists' value of Hongcun and Xidi traditional villages with the MEC theory, for tourists born in the $60 \mathrm{~s}, 70 \mathrm{~s}, 80 \mathrm{~s}$ and $90 \mathrm{~s}$, as well as after the $90 \mathrm{~s}$. The current generation commonly in Chinese society is a subgroup with a cycle of 10-year, as they all have experienced some major external events and share common values [34-37], for Chinese people in each decade.

\section{Research Design}

\subsection{Typicality of Hongcun and Xidi}

At present, according to the protection list of Chinese traditional villages with the collection of five batches of 6,819 Chinese traditional villages, the spatial distribution of Chinese traditional villages shows four major gathering areas: Anhui, Zhejiang and Jiangxi, the junction of Hebei, Shandong and Henan, the junction of Guizhou, Guangxi and Hunan, and northwestern Yunnan [38].

The tourism development of traditional villages in Huangshan City, in the agglomeration area of Anhui, Zhejiang and Jiangxi, has reached a certain scale, gains 
benefits and obtains the popularity, which the tourism development of Hongcun and Xidi is the most typical one .

\subsection{The Collection and Analysis of Data}

This research uses the soft ladder method of MEC theory for collection and analysis of data. From August 2018 to January 2019, 71 tourists who visited Hongcun and Xidi, Yi County, Anhui Province were interviewed in depth. The researcher recorded the entire interview process after requesting the interviewees' permissions. Each interviewer's interview lasted 30-60 minutes. The interview was ended when the interviewee was unable to provide more information, and the recording was edited into script. Due to insufficient information, the interviews of 11 tourists were deleted among the 71 interviews. In the end, there were 60 samples retaining for analysis and research consisting of 15 samples of each generation in $60 \mathrm{~s}, 70 \mathrm{~s}, 80 \mathrm{~s}$, and $90 \mathrm{~s}$ (Table 1) .

The analysis process of the research is structured in four steps. In the first step, the texts converted from 60 interview recordings were conceptually refined according to the MEC theoretical model framework, and categorized into three aspects-attributes, consequences, and value. The aspect of attributes in traditional villages is purified from the question of tourists" interviews, "What do you think are the characteristics of this traditional village tourism?", then the consequences from "What is the influence or result of the characteristics of these traditional villages to you?", and the value from "Why is this tourism result or influence important to you? ". In the second step, construct an association matrix of "attributes-results" and "results-values", based on the correlation of attribute, result, and value refined in the former step, to quantify the relation of "attributes-results" and "results-values". In the third step, according to the statistics of the number in unit of the association matrix constructed in the second step and the number of relations of concepts, a cut-off value needs to be determined during the analysis of the HVM. Reynolds and Gutman (1984)[39] and Bagozzi and Dabholkar (1994) [40]considered that the cut-off value in the soft step method is relatively appropriate 1-5. Therefore, in this study, the cut-off value threshold is determined as 2 with the soft step method, and the association number below threshold 2 is considered as a special case or an obvious exception. In the fourth step, the chain relation of " attribute, result, value" has been forged, through filtering the data of "attribute-result" and "result-value" in correlation matrices on the basis of the threshold 2 defined in the third step, and drawing the HVM with the threshold not less than 2.

Table 1 Demographic Information statistics of interviewees $(\mathrm{n}=60)$

\begin{tabular}{|c|c|c|}
\hline \multicolumn{2}{|c|}{ Demographic Information } & $\begin{array}{c}\text { Demogr } \\
\text {-aphic } \\
\text { statistics } \\
(\%)\end{array}$ \\
\hline \multirow{2}{*}{ Gender } & Male & $41.7 \%$ \\
\cline { 2 - 3 } & Female & $58.3 \%$ \\
\hline
\end{tabular}

\begin{tabular}{|c|c|c|}
\hline \multirow{4}{*}{$\begin{array}{c}\text { Educati } \\
\text { on Degree }\end{array}$} & $\begin{array}{c}\text { Secondary Vocational School } \\
\text { Qualification }\end{array}$ & $5.0 \%$ \\
\cline { 2 - 3 } & $\begin{array}{c}\text { Senior School or } \\
\text { Bachelor Degree /Collage } \\
\text { Degree }\end{array}$ & $66.7 \%$ \\
\cline { 2 - 3 } & $\begin{array}{c}\text { Graduate Degree or } \\
\text { Above }\end{array}$ & $28.3 \%$ \\
\hline \multirow{4}{*}{$\begin{array}{c}\text { Process } \\
\text { ion }\end{array}$} & Civil Servant & $6.7 \%$ \\
\cline { 2 - 3 } & $\begin{array}{c}\text { Managerial Personnel in } \\
\text { Enterprises and Institutions }\end{array}$ & $6.7 \%$ \\
\cline { 2 - 3 } & Owner of Individual Ent- \\
& erprise & $23.3 \%$ \\
\cline { 2 - 3 } & $\begin{array}{c}\text { Practitioners in } \\
\text { Education/Research/Culture }\end{array}$ & $8.3 \%$ \\
\cline { 2 - 3 } & Freelance & $41.7 \%$ \\
\cline { 2 - 3 } & Student & $3.3 \%$ \\
\cline { 2 - 3 } & Others & $5.0 \%$ \\
\hline
\end{tabular}

\section{Research Findings}

Based on the further analysis of the correlation between "attribute-result" and "result-value", This study has constructed the portrayed 39 MEC value chains (Table 2) with 22 categories. And there are 11 attributes of Hongcun and Xidi recognized by tourists born in the $60 \mathrm{~s}$, 70s, 80s and 90s: ancient buildings/home-stay, traditional village environmental atmosphere, Huizhou culture, sculpture/couplet, residents' lifestyles, traditional village layout, Anhui cuisine, traditional village water system, family parent-child trips, local specialty and natural landscape around traditional villages. The 9 kinds of values "inner harmony, satisfaction, self-improvement, sense of belonging, beautiful world, family happiness, eternal life, delight, and self-realization" are achieved though the three aspects of "attributes-consequences-value".

Ancient buildings/ home-stay refer to ancient buildings in traditional villages and home-stays with local cultural characteristics that are transformed by ancient buildings. Then, traditional village environmental atmosphere represents the atmosphere that is formed by the cultural and natural environment of the traditional village. Huizhou culture is the traditional culture with local characteristics of Huizhou. And sculpture/couplet refers to the sculptures in Huizhou buildings and couplets that reflect the traditional culture of Huizhou. The lifestyle of residents indicates the idyllic slow lifestyle of "beginning with sunrise and ending at sunset". Furthermore, the traditional village layout refers to the space arrangement generally formed in traditional villages. Huizhou cuisine denotes local dishes with Huizhou characteristics, such as stinky mandarin fish, hairy tofu, etc. Moreover, traditional village water system includes streams or ponds in traditional villages that represent the functions of living, production, or fire fighting. Family parent-child trip refers to tourism projects in traditional villages that are suitable for families or parents and children. Local specialty refers to tourism products with local characteristics, such as wood carving, brick carving, stone carving, bamboo shoots, etc. Besides, natural 
landscapes indicates the scenery that is formed by artificial planting or nature.

Table2 MEC value chain of Hongcun and Xidi tourists

\begin{tabular}{|c|c|c|c|c|c|c|c|}
\hline & Attributes & Consequences & Value & 60 & 70 & 80 & 90 \\
\hline MEC1 & $\begin{array}{c}\text { Traditional Village } \\
\text { Environmental } \\
\text { Atmosphere }\end{array}$ & $\begin{array}{c}\text { Harmony between Heaven } \\
\text { and Human }\end{array}$ & Inner Harmony & $\sqrt{ }$ & & & \\
\hline MEC2 & $\begin{array}{c}\text { Traditional Village } \\
\text { Environmental } \\
\text { Atmosphere }\end{array}$ & Escapism & Inner Harmony & & $\sqrt{ }$ & $\sqrt{ }$ & \\
\hline MEC3 & Huizhou Culture & $\begin{array}{c}\text { Cultural Experience and } \\
\text { Inheritance }\end{array}$ & Sense of Belonging & $\sqrt{ }$ & $\sqrt{ }$ & $\sqrt{ }$ & $\sqrt{ }$ \\
\hline MEC4 & Sculpture/Couplet & Craftsman Spirit & Sense of Belonging & $\sqrt{ }$ & & & \\
\hline MEC5 & Ancient Buildings & $\begin{array}{c}\text { Accommodation } \\
\text { Experience }\end{array}$ & Satisfaction & & $\sqrt{ }$ & & $\sqrt{ }$ \\
\hline MEC6 & Ancient Buildings & Photo-taking and Posting & Satisfaction & & & & $\sqrt{ }$ \\
\hline MEC7 & Local Specialty & Shopping Experience & Satisfaction & & $\sqrt{ }$ & $\sqrt{ }$ & \\
\hline MEC8 & Residents' Lifestyles & Novelty Experience & Satisfaction & & & & $\sqrt{ }$ \\
\hline MEC9 & Anhui Cuisine & Culinary Experience & Satisfaction & $\sqrt{ }$ & $\sqrt{ }$ & $\sqrt{ }$ & $\sqrt{ }$ \\
\hline MEC10 & $\begin{array}{c}\text { Natural Landscape } \\
\text { around Traditional } \\
\text { Villages }\end{array}$ & Beauty & Beautiful world & & & & $\sqrt{ }$ \\
\hline MEC11 & $\begin{array}{c}\text { Traditional Village } \\
\text { Layout }\end{array}$ & A Landscape Painting & Beautiful world & & & $\sqrt{ }$ & $\sqrt{ }$ \\
\hline MEC12 & $\begin{array}{c}\text { Traditional Village } \\
\text { Environmental } \\
\text { Atmosphere }\end{array}$ & Beauty & Beautiful world & $\sqrt{ }$ & $\sqrt{ }$ & & \\
\hline MEC13 & $\begin{array}{c}\text { Ancient } \\
\text { Buildings/Home-stay } \\
\end{array}$ & A Landscape Painting & Beautiful world & & $\sqrt{ }$ & & \\
\hline MEC14 & $\begin{array}{c}\text { Ancient } \\
\text { Buildings/Home-stay }\end{array}$ & Knowledge Enhancement & Self-improvement & $\sqrt{ }$ & $\sqrt{ }$ & $\sqrt{ }$ & $\sqrt{ }$ \\
\hline MEC15 & $\begin{array}{l}\text { Family Parent-child } \\
\text { Trip } \\
\end{array}$ & Knowledge Enhancement & Self-improvement & & $\sqrt{ }$ & $\sqrt{ }$ & \\
\hline MEC16 & Huizhou Culture & Knowledge Enhancement & Self-improvement & & $\sqrt{ }$ & & $\sqrt{ }$ \\
\hline MEC17 & Sculpture/Couplet & Knowledge Enhancement & Self-improvement & & & & $\sqrt{ }$ \\
\hline MEC18 & $\begin{array}{l}\text { Traditional Village } \\
\text { Water System }\end{array}$ & Ecological Protection & Sense of Security & $\sqrt{ }$ & $\sqrt{ }$ & & \\
\hline MEC19 & $\begin{array}{c}\text { Traditional Village } \\
\text { Water System }\end{array}$ & Ancients' Intelligence & Intelligence & $\sqrt{ }$ & & & \\
\hline MEC20 & Residents' Lifestyles & Idyllic Life & Eternal Life & & $\sqrt{ }$ & & \\
\hline MEC21 & $\begin{array}{c}\text { Traditional Village } \\
\text { Environmental } \\
\text { Atmosphere }\end{array}$ & Hygiene & Clean & & $\sqrt{ }$ & & \\
\hline MEC22 & $\begin{array}{c}\text { Traditional Village } \\
\text { Environmental } \\
\text { Atmosphere }\end{array}$ & Escapism & Delight & & & $\sqrt{ }$ & \\
\hline
\end{tabular}




\section{Research Conclusion}

This research has constructed a sustainable development model of Huizhou traditional villages based on the tourists' value (Figure 1), combining with the theoretical model of the means-end chain [41] and the MEC value chain of tourists in Hongcun and Xidi traditional villages(Table 2).

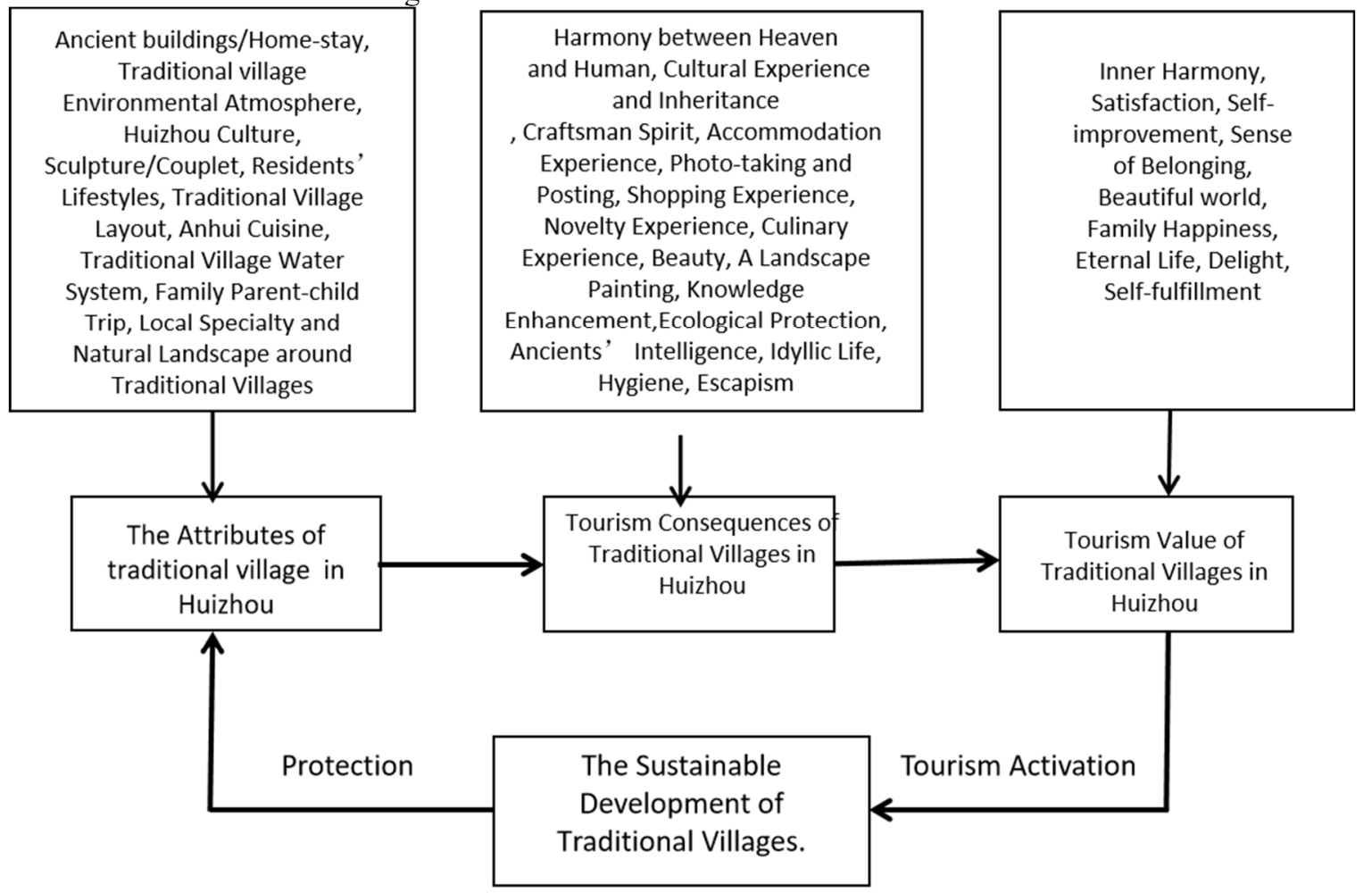

Figure 1 The Sustainable Development Model of Traditional Villages Based on Tourists' Value

\section{Source: Drawn by the Autho}

The process that tourists has experienced 11 key attributes of traditional villages in Huizhou, got 16 tourism consequences, and realized 9 tourism values of traditional villages in Huizhou, reaches the highest demand of tourists, the ultimate value of tourists, reflecting the spiritual needs of tourists in Huizhou traditional villages. The study finds that the circular relationship, formed by the interaction of "attributes-results-values" of traditional villages, contributes to the sustainable development of traditional villages in Huizhou, only if the 11 key attributes should be preserved specially, and the 9 ultimate values of tourists should be fully activated in segment of market development of traditional villages' tourism.

Therefore, in the tourism marketing process of Huizhou traditional villages, it is essential to establish the new tourism image of Huizhou traditional villages, starting from the motivation of attribute and value of traditional villages, to activate their attributes and values, with highlighting promotion of tourists' value "inner harmony, satisfaction, self-improvement, sense of belonging, beautiful world, family happiness, eternal life, delight, and self-realization", which is created by the "ancient buildings/home-stay, traditional village environmental atmosphere, Huizhou culture, sculpture/couplet, residents' lifestyles, traditional village layout, Anhui cuisine, traditional village water system, family parent-child trips, local specialty and natural landscape around traditional villages". Targeting one or several tourism market segments of the tourists in $60 \mathrm{~s}$, $70 \mathrm{~s}, 80 \mathrm{~s}$ and $90 \mathrm{~s}$, it focuses on tourism promotion and marketing target individually, combining $8 \mathrm{MEC}$ chains for tourists in the $60 \mathrm{~s}, 13 \mathrm{MEC}$ chains for tourists in the $70 \mathrm{~s}, 9 \mathrm{MEC}$ chains for tourists in the 80s and $10 \mathrm{MEC}$ chains for tourists in the $90 \mathrm{~s}$ with traditional village attributes and tourism consequences concerned by tourists in 60s, 70s, 80s and 90s. Meanwhile, promotion methods like reputation, Wechat, Weibo, Douyin and online celebrity, should be valued, due to the two ways of acquiring tourism information through friends/acquaintances and the Internet for tourists in Huizhou traditional villages.

In the future, it will investigate the "attributes, results, value" motivation and MEC value chains with large sample collected from national traditional village tourists, which improves the applicability of the research. In the meantime, the study will explore the relation between tourists' value and traditional village activation in depth with construction of protection and activation model of traditional villages, exploration of the new tourism format and tourism products, segment marketing, service level improvement,which activates traditional villages, to achieve rural revitalization and contribute to tourism activated protection and sustainable development of traditional villages. 


\section{References}

1. China Encyclopedia Editorial Committee. (2008). Encyclopedia of China Volume 18. Beijing Encyclopedia of China Publishing House

2. Xia Zhengnong \& Chen Zhili, ed. (2011) Cihai (6th Edition) collection. Shanghai: Shanghai Dictionary Publishing House. 355

3. Ministry of Housing and Urban-Rural Construction,et c. (2012) Notice on the investigation of traditional villages. Source:http://www.gov.cn.

4. Klenosky, D. B., Gengler, C. E., \& Mulvey, M. S. (1993) Understanding the Factors Influencing Ski Destination Choice: A Means-End Analytic Approach. Journal of Leisure Research, 25(4), 362-379.

5. Sun, P. C., Cheng, H. K., \& Finger, G. (2009) Critical Functionalities of a Successful E-Learning System - An Analysis from Instructors' Cognitive Structure Toward System Usage. Decis Support Syst, (48), 293-302.

6. Mei Y. J. \& Tsu M. Y. (2016) The Effect of Consumer Values on the Brand Position of Green Restaurants by Means-End Chain and Laddering Interviews. Service Business, (10), 223-238.

7. Cui Haiyang, \& Gou Zhihong. (2019) Research Progress and Prospect on Protection and Utilization of Traditional Villages. Guizhou Ethnic Studies (12).

8. Jiang Haiping, Wang Yanhua, \& Li Jinglong. (2009) Research on Development Models of Ancient Villages based on Community Management-A Case Study of World Cultural Heritage - Xidi Village and Hongcun Village. East China Economic Management, 23(08), 24-28.

9. Liu Pei lin, Liu Chunla.. (2010) Typical Modes of Valley Economy and Its Enlightenment on Protecting Ancient Villages in the Mountains Areas of Beijing. Economic Geography,30(12), 1944-1949.

10. Wei Fengqun. (2010) Mixed - effect Model of Traditional Ancient Village Protection and Tourism Development. Journal of Arid Land Resources and Environment, 24(10), 197-200.

11. Li Lianpu. (2013) Tourism Sustainable Development of Village Based on Multi-attributes: A Case of Study National Historic Cultural Village. Human Geography,30(12), 1944-1949.

12. Wu YingQi.(2017) On the tourism utilization of endangered cultural heritage from the perspective of Anthropology - A Case of Daimei Ancient Village, Longhai City, Fujian Provence. Southern Cultural relics, (2), 266-270.

13. Wu Bihu. (2016) Protection and Activation of Traditional Villages Based on Rural Tourism. Social Scientist, 226(2), 7-9.

14. Xu Wei, \& Wang Xinxin.(2011) A Study on Authentic Perception of Tourists and its Impact on their Satisfaction and Behavioral Intentions-A Case of Ancient Village Tour. Economic Management(4), 111-117.

15. Wang Chunyang,\& Huang Fucai.(2012) An Empirical Study on the Definition and Classification of Stakeholders in Village Heritage Sites: A Case Study of Kaiping Watchtower and Village. Tourism Tribune, 27(8), 88-94.

16. Li Fan, \& Cai Zhenyan.(2007) A Study on Stakeholders in Tourism Development of Ancient Villages - Taking Daqitou Ancient Village as a Case. Tourism Tribune, 22(1), 42-48.

17. Che Zhenyu. (2017) Spatial form evolution from traditional villages to small towns in tourism development. Tourism Tribune,32(01), 10-11.

18. Feng Shuhua.(2013) Discussion of Ancient Villages'Symbiosis Evolution Model Based on Symbiosis Theory. Economic Geography, 33(11), 155-162.

19. Tang Wenyue, Zhang Jie, Luo Hao, Lu Song, \& Yang Xiaozhong.(2008) Relationship between the Place Attachment of Ancient Village Residents and Their Attitude towards Resource Protection- A Case Study of Xidi,Hongcun and Nanping Villages. Tourism Tribune,23(10), 87-92.

20. Li Wenbin, \& Zhang Hongmei.(2010) An Empirical Study of Tourist Perceived Value Model of Ancient Villages:A Case Study on Zhangguying Village. Tourism Science, 24(2), 55-63

21. Rajaratnam, S. D., Munikrishnan, U. T., Sharif, S. P., \& Nair, V. (2014) Service Quality and Previous Experience as a Moderator in Eetermining Tourists' Satisfaction With Rural Tourism Destinations in Malaysia: A Partial Least Squares Approach. Procedia - Social and Behavioral Sciences, 144(144), 203-211.

22. Wang Ying, \& Quan Junyan.(2017) Study on Protection and Development of Ancient Villages based on the Emerging Market of 90s. Tourism Forum, 10(6), 85-96.

23. $\mathrm{Xu}$ Chuncheng, \& Wan Zhiqin.(2015) Argumentation on Basic Thoughts of Traditional Village Protection. Journal of Huazhong Agricultural University (Social Sciences Edition) (6), 58-64.

24. Li Weihua, Zhao Zhenbin, \& Li Yanhua.(2006) An Analysis of Comprehensive Perception and Variations of Residents in Ancient Village Tourism Areas: a Case Study of Dangjiacun in Hancheng, Shaanxi. Tourism Science, 20(6), 52-58.

25. Hu Daosheng . (2002) A Study on the Tourism Development of the Ancient Villages

- A Case Study in Yixian County, Anhui Province. Human Geography, 17(4), 47-50.

26. Falak, S., Chiun, L. M., \& Wee, A. Y. (2014) A Repositioning Strategy for Rural Tourism in Malaysia-Community's 
Perspective. Procedia-Social and Behavioral Sciences, 144, 412-415.

27. Tang Wenyue.(2011) The Characteristics of Place Attachment of Ancient VILLAGE Residents-A Case Study of Xidi, Hongcun and Nanping villages, southern Anhui. Human Geography(3), 51-55.

28. Amir, A. F., Ghapar, A. A., Jamal, S. A., \& Ahmad, K. N. (2015) Sustainable Tourism Development: A Study on Community Resilience for Rural Tourism in Malaysia. Procedia-Social and Behavioral Sciences, 168(9), 116-122.

29. Vitasurya, V. R. (2016) Local Wisdom for Sustainable Development of Rural Tourism, Case on Kalibiru and Lopati Village, Province of Daerah Istimewa Yogyakarta. Procedia - Social and Behavioral Sciences, 216, 97-108.

30. Lu Song, Chen Siyi, \& Pan Hui.(2012) Preliminary Study on the Assessment Tourism Sustainability in Ancient Village - Taking World Cultural Heritage Site Hongcun as an Example. Tourism Tribune, 25(01), 17-25.

31. Laird, J. (1961) The Idea of Value. Cambridge: Cambridge University Press.

32. Li Deshun.(2013) Axiology. Beijing: China Renin University Press.

33. Wan Junren. (1992) An Extension of Truth and Value and Their Relationship. The Journal of Humanities, (6), 33-41.

34. Zhang Yongjie, \& Cheng Yuanzhong.(1988) The Fourth Generation. Beijing: China Eastern Press. 61-33.

35. Yu Shilan.(2013) Evolution of the Contemporary Chinese Values. Journal of Shijiazhuang University of Economics, (5), 117-120.

36. Jiang Chang.(2014) Discussion on the Construction of Modern Chinese Value. Marxism and Reality, (4), 147-154.

37. Liu Minzhu, \& Feng Yanli.(2016) Discussion on Connotation of Modern Chinese Value. Discovery(1), 154-159.

38. Kang Jingyao, Zhang Jinhe, Hu Huan, Zhou Jun, \& Xiong Jie.(2016) Analysis on the spatial distribution characteristics of Chinese traditional villages. Progress in Geography, 35(7), 839-850.

39. Reynolds, T. J., \& Gutman, J. (1984) Advertising is Image Management. Journal of Advertising Research, 24(1), 27-37.

40. Bagozzi, R. P., \& Dabholkar, P. A. (1994) Consumer Recycling Goals and Their Effect on Decisions to Recycle, A Means-End Chain Analysis. Psychology \& Marketing,11(4), 313-340.

41. Olsonj. C, \& Reynold, T. J. (1983). Understanding Consumer Decision Marking: The Marking Means-End Approach to Marketing and Adverstising Strategy. London: Psychology Press. 